\title{
Bible: The Story of the King James Version, I6I I- 20II, by Gordon Campbell
}

Oxford: Oxford University Press, 20 10 | xiii + 354 pages | ISBN: 978-0-19-955759-2 (hardback) £16.99

Professor Campbell characterises his contribution to King James Bible (KJB) studies as "an affectionate biography” (vi). The companion volume to OUP's anniversary issue of the I6I I Bible (itself edited by

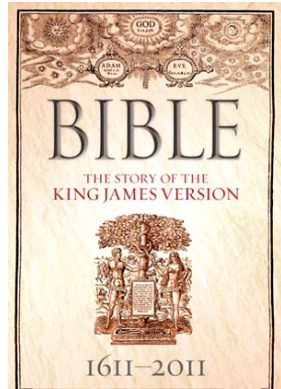

GORDON CAMPBELL Campbell), this is a book intended for the general reader. It comprises an introduction and thirteen chapters, supplemented by thirty-seven black-and-white illustrations, two appendices, a bibliography and index.

The introduction includes a brilliantly compact summary of the emergence of different English Churches from the I 500 s onwards (marred only by the most common of slips in reference to the "United Reform [sic] Church"the correct title is of course "Reformed"). His clarification of the nuances behind "evangelical" discourse is similarly concise and helpful. Indeed, a capacity to be both succinct and precise is evident throughout the book.

Dispatching the pre-history of the English Bible in a single chapter, Campbell then gives considerable attention to the detail of production, including ideology (the reasons for its commission and the commitments of its translators), the translation process, and the physical object. The structure of chapter 2 ("The Commissioning") is well thought out, offering a commentary on the translators' principles (both Bancroft's instructions and the post facto reports of Samuel Ward to the Synod of Dort). Again, there are one or two issues that ought to have been picked up by the proofreader-a most odd reference to the practicalities of "rule 4," where surely rule 8 is intended (42), and an awkward transition that implies the inclusion of the Apocrypha was due to (rather than in spite of) Puritan objections (45), which is probably not what Campbell intended.

The third chapter is illustrated with excellent reproductions of the workin-progress; photographs of the Bodleian's annotated Bishops' Bible support Campbell's repeated call for its unbinding (to permit further study). An entertaining pen-portrait of each Company, complemented by a more detailed appendix, underscores the erudition and superlative linguistic skills of the known translators, and the variation between the groups (perhaps one might 
add that it was not only learned men who had the Syriac New Testament in their collections-Durham Cathedral library preserves a copy that was once the property of Arbella Stuart, cousin to King James).

The chapter on translation is the first to consider the particular linguistic features of the KJB. Campbell provides insight into its relationship with both contemporaneous spoken (informal) and Shakespearean (formal) English, a comparison to which he returns when considering its eighteenth-century reception.

Chapter 5 attends to physical features of the first edition, including its sometimes surprising iconography. The New Testament title page was taken over from the 1602 Bishops' Bible, which introduced representation of the Trinity, and also included each of Israel's twelve tribes using symbols that draw on Hebrew sources (96); their origin bears further enquiry, but Campbell is incorrect in assuming that the Bishops' designer had "learned advice." Prior editions of the Geneva Bible (ca. I 599-1602) carry a very similar design, and the mirroring in the tribal icons lends support to an initial suspicion that the designer has copied these motifs (along with dove and lamb of the Trinity). A second oversight concerns the border designs; these were freshly prepared for the I6I I Bible, and pay homage to the king through an interweaving of English rose, Scots thistle, Irish harp (and French fleur-delys), a point which escapes Campbell.

Chapters 6-8 sketch the development of the text (approaches to editing, changes to spelling, punctuation, etc.) and its reception, century by century. Text landmarks include Cambridge University's successful challenge to Barker's bible-printing monopoly (I629), Parris and Blayney's addition of archaisms during the I 700 (ensuring every nominative plural "you" became "ye"), and the divergence of American and British KJBs by virtue of the first US attempt at standardisation (published in I 856). In terms of cultural reception, Vicesimus Knox's 1782 verdict on the "impropriety of publicly adopting a new translation of the Bible" (cited by Campbell, I46) is seen as a turning point, while the various Bible Societies contributed to its bestselling status with their mammoth distribution efforts. It would be interesting to see Campbell's assertion that the perceived poetic qualities of the KJB reflect its construction for reading aloud, when contrasted with modern texts designed for silent consumption, explored more thoroughly.

Chapter 9 is dedicated to the Cambridge Paragraph Bibles. Campbell is probably right in his assertion that the paragraphs of their title are not the strongest selling point; but his praise for the efforts of Scrivener and Norton 
(the latter especially) is well placed: "By the measure of textual scholarship, there are no better editions of the KJV" (I77).

As colonial powers shifted across the Atlantic, argues Campbell, so did the story of the KJB (or at least its centre of gravity). In chapter Io, he constructs a narrative of US history that intertwines the rise of the conversion experience, and fundamentalist Christianity, with the influence of religion on politics, and demonstrates the significance of the KJB for both Democrat and Republican politicians.

No "biography" of the KJB would be complete without an appearance from its descendants, including the Revised Version. Campbell attributes the RV's popular failure to a lack of scholarly agreement over the Greek texts; though Westcott and Hort's championship of the Sinaiticus-Vatican manuscripts is now accepted, it was controversial in the late I8oos, and John William Burgon performed an excellent character assassination grounded in his own support of the Textus Receptus.

Much of twentieth-century reception is occupied by the contest between those who conserve prophetic and doctrinal readings, and others willing to separate the text from its traditional baggage. Against this somewhat pessimistic backdrop, Campbell highlights the surprising ecumenical coalitions which accompanied new Bible versions.

Considering other twentieth-century treatments of the KJB, Campbell seems to misread T. S. Eliot's critique of others' praise for "the Bible as literature." Eliot's point is not that its literariness is God-given, but that its primary cultural status "as the report of the Word of God" accounts for its "literary influence" (Eliot's 1935 essay on "Religion and Literature," cited by Campbell, 255; emphasis changed). The KJB could not have become the apex of the literary standards it helped shape, had it not been influential for non-literary reasons. There are other occasions where one might quarrel with Campbell's reading of case studies, but given the brevity necessitated by the book's format this is perhaps unfair.

Campbell's survey of the KJB's position today (chapter I3) is less substantial than the other chapters, and the closing section is lumbered with that slightly anecdotal quality which often plagues attempts at near-contemporary history. Moreover, there are hints of a romantic allegiance in his conclusion, that this is "the Bible of the heart" (275); perhaps our observer is not wholly disinterested.

Reviewing the work in full: in terms of presentation, the illustrations are consistently excellent, but the explanation often precedes the view, such that 
a simple "see overleaf" would be beneficial. Indeed, internal cross-referencing is curiously absent from the first several chapters, with the exception of KingJames-Only-ism which repeatedly rears its head in anticipation of the final chapter. This points to a deeper issue in the context of an academic review: for those biblical scholars who have been invited to speak beyond their expertise in this special anniversary year, Bible has doubtless been a handy point of reference; and those with considerable expertise in the field will surely have had no difficulty debating the finer points of Campbell's interpretations; but for those now engaged in an academic study, the absence of footnotes and other critical apparatus render Campbell's work largely impotent. This is in spite of the thorough and extensive bibliography (a list by chapter or theme may have been more accessible).

Campbell purposefully restricts his sphere of reference to "England and the United States" (6), an understandable decision given the need to impose some limits upon the project. However, it is indicative of a larger disappointment: the KJB was commissioned by a Scotsman and is owned by English-speakers across the globe; Bible: The Story of the King James Version, I6II-20II is one man's Anglocentric account of 400 years. In 201 I, might we not expect greater attention to the marginalised others? In fact, there is surprisingly little beyond the confines of the commonplace where the KJB's reception is concerned-its standing as the exemplar of English literature and language, and its influence on US politics. (By way of an exception, it is good to see the Scofield Reference Bible placed under the spotlight in chapter I 2, given the ongoing cultural impact of Scofield's eschatological readings.) There is not much that is new.

All this is perhaps an unnecessary detraction; what Campbell aims to do, he does, and what he does, he does decently well. A mastery of the English language is evident throughout; describing the "doctrine of the [KJB's] verbal inspiration" as a nineteenth-century "shibboleth" (66) is a particularly fine case in point. One suspects that such flourishes come naturally for Campbell, though there is a concurrent risk that his vocabulary will prove too great a challenge for the less intellectual reader. Nonetheless, the combination of such verve with occasional first-person intrusions (the style hints at his talent for public-speaking) creates a book full of authorial character. The result is genuinely entertaining as well as informative. With individual chapters sufficiently self-contained to allow the reader to dip in and out, this is, in short, an excellent book for the coffee table, though not the best tool for the study. 
Of course, any scholar choosing to explore the phenomena of this 40oth anniversary (and there is work to be done) may well include this volume as an object for analysis.

I. C. Hine

The University of Sheffield 